\title{
Karuara: a persistência de uma crença Tupinambá
}

Roque de Barros Laraia ${ }^{1}$

\section{Resumo}

A partir dos significados expressos pela palavra karuara do Tupinambá, tal qual registrada no século XVI, pesquiso, por um lado, os vários significados que essa palavra adquiriu durante a formação da cultura brasileira e, por outro lado, os significados de palavras cognatas encontradas em outras línguas Tupí, concluindo pela persistência não apenas dos significados básicos da palavra através dos povos Tupí-Guaraní, mas também pela manutenção da crença comum em karuara.

Palavras-chave: Karuara, línguas e culturas Tupí-Guaraní, significados simbólicos, persistência de crenças, etnografia Tupí.

\begin{abstract}
Beginning by the meanings expressed by the Tupinambá word karuara, as recorded in the sixteenth century, I survey the various other meanings it acquired during the development of the Brazilian culture, as well as the meanings of the cognate words found across other Tupian languages, concluding for the persistence not only of the basic meanings of the word across Tupí-Guaraní peoples but also of their common karuara belief.
\end{abstract}

Keywords: Karuara, Tupí-Guaraní languages and cultures, symbolic meanings, beliefs persistence, Tupian ethnography.

\section{Introdução}

Este artigo ${ }^{2}$ tem como objetivo definir os significados da palavra Tupinambá karuara, registrada por vários cronistas seiscentistas e ainda encontrada entre vários grupos contemporâneos da família linguística TupíGuaraní. Trata-se não apenas da análise de um vocábulo que persiste há mais de 500 anos, mas também do conjunto de crenças que está contido em seus significados. Antes de nos referimos aos aspectos simbólicos que estão associados a essa palavra, pretendemos mostrar como ela sobreviveu ao desaparecimento da cultura Tupinambá e passou a fazer parte do vocabulário de nossa língua.

\footnotetext{
1 Departamento de Antropologia, Universidade de Brasília.

2 Este artigo é resultado de pesquisa realizada com o apoio do CNPq, na qualidade de bolsista de produtividade científica 1-A.
} 
A palavra foi, por exemplo, registrada por Gabriel Soares de Souza, que afirmou serem os Tupinambá “...doentes de corrimentos, o que chamam caruara, de que lhes doe as juntas, das quais são os feiticeiros grandes médicos..." (In: Tratado descritivo do Brasil em 1587. Cia. Editora Nacional, São Paulo, 1971:38).

Embora os Tupinambá tenham sido considerados extintos desde os meados do século XVII, o referido vocábulo continuou existindo e encontrase citado em vários dicionários da língua portuguesa, como nos mostram os exemplos abaixo:

Caruara, s.f. (Tupí-Guaraní) 1. Feitiço, mau olhado, quebranto. 2. (Nordeste) Vento de trovoada que aparece em janeiro. 3. Enfermidade sem causa aparente. 4. Achaque. 5. Dor reumática. 6. Paralisia da articulação dos bezerros e outros animais recém nascidos. Doença das aves domésticas. (verbete do Dicionário Brasileiro da Língua Portuguesa. Enciclopédia Britânica do Brasil/ Cia. Melhoramentos, São Paulo, 12 edição, 1990, $1^{\circ}$ volume, p. 372).

Idêntico verbete é apresentado na página 444 do Michaelis, Moderno Dicionário da Língua Portuguesa. Melhoramentos, São Paulo, 1998.

Caruara. Mau olhado, quebranto, achaque. Enfermidade provocada por feitiço. Medo, pavor. Impotência funcional dos membros inferiores. Nordeste, paralisia das articulações dos bezerros e outros animais recém-nascidos. Amazônia, dor reumática. II. Abelha muito pequena.

Aparece também em Silveira Bueno, com os seguintes exemplos:

Caruara. Adj. Aquele que come. Diz Teodoro Sampaio:

a comichão, o prurido, a sarna, boubas. No Norte do Brasil, é uma moléstia que ataca o gado trazendo-lhe inchação e paralisia nas pernas e corrimentos. Com o mesmo nome se conhece uma formiga que dá nas árvores, cujas mordeduras coçam como sarna e também uma qualidade de abelha, cujo mel é nocivo... (In: Francisco da Silveira Bueno, Vocabulário Tupi-Guaraní, $5^{\mathrm{a}}$ edição, Brasilivros Editora, São Paulo, 1987).

Antônio Geraldo da Cunha em seu Dicionário Histórico das Palavras Portuguesas de Origem Tupi (Cia. Melhoramentos/Editora da UnB, São Paulo e Brasília, 1999, p. 107), além de repetir os significados encontrados nos outros verbetes, mostra que a palavra pode ser encontrada nas páginas de um dos mais importantes clássicos de nossa literatura: “...que se lhe antolhe quebradas, acervos de pedras, coivaras, moitas de espinhos, os barrancos 
de ribeirões, nada lhe impede encalçar o caruara desgarrado" (Euclides da Cunha, Os Sertões, $1^{\text {a }}$ edição, 1902, p. 107). Valnice Galvão, em seus comentários da edição, nos mostra que o vocábulo, no entanto, só apareceu na primeira edição da obra magistral, tendo sido substituído pelo próprio Autor, a partir da $2^{\mathrm{a}}$ edição, pelo termo "garrote".

O que pretendemos demonstrar com base em várias etnografias Tupí, produzidas na atualidade, é que as traduções feitas no passado e os significados atribuídos nos verbetes do presente não têm correspondência direta com os significados atribuídos pelos Tupinambá e pelos Tupí contemporâneos ao vocábulo. Este fato pode ser explicado pela precariedade da comunicação linguística entre os Tupinambá do século XVI e os primeiros europeus com quem entraram em contato. A nossa hipótese é que se trata de uma confusão entre os causadores e as consequências. Para os Tupinambá os karuara eram os causadores das doenças, para os seus observadores a palavra referia-se a alguns tipos de doenças.

Em sua viagem pelo rio Xingu, em 1896, Henri Coudreau descreveu a Pedra do Caruara:

Dá-se o nome de Pedra do Caruara a um conjunto de rochedos, situados na ponta superior de uma ilhota do meio do Xingu. Esta ilhota teria sido antigamente a sede de uma importante maloca, mas isso, numa época muito remota, a julgar-se pela quantidade de machados de pedra grosseiramente polidos que se encontrariam a uma certa profundidade sob o solo, quer enterrados pela mão do homem quer recobertos pelas sucessivas vegetações (a palavra caruara, em Jurúna, refere-se a qualquer coisa misteriosa, sagrada, santa). O conjunto desses rochedos da Caruara mede de 5 a 6 metros de altura, havendo algumas rochas assentadas horizontalmente umas sobre as outras, como bigornas, deixando entre si espaços que parecem corredores, pequenos compartimentos ou nichos (Coudreau 1977:50).

\section{A palavra karuara através de povos Tupí-Guaraní}

O nosso interesse pelo vocábulo é antigo, remonta ao nosso primeiro período de campo entre os Suruí, do sudeste do Pará ${ }^{3}$ A primeira vez que o ouvimos foi quando esses índios relutaram em penetrar em uma gruta, itakuara, por ser a mesma habitada por muitos karuara. De fato, o termo não me era totalmente desconhecido.

\footnotetext{
${ }^{3}$ Os Suruí são hoje conhecidos pelo termo Aikewára.
} 


\subsection{Tenetehára}

A palavra karuara apareceu mencionada por Curt Nimuendajú, em 1945, quando este descreve a iwaga, moradia dos ancestrais dos Tembé:

Perto da casa de Mahira está uma grande aldeia. Seus habitantes vivem magnificamente. Para seu sustento diário necessitam apenas de algumas pequenas frutas semelhantes à cuia; sua plantação não necessita cuidados, ela se planta e se colhe sozinha. Mahira e seus companheiros no campo de ikawera tem o nome de karuara. Quando envelhecem não morrem, mas tornam-se novamente jovens. Cantam, dançam e celebram festas sem cessar. (Niemandajú 1916).

Outra menção foi encontrada em Charles Wagley e Eduardo Galvão:

Os Tenetehara se referem aos sobrenaturais pela designação genérica de Karowara, porém os distinguem pelo menos em quatro categorias: criadores ou heróis culturais; os donos das florestas, das águas e dos rios; os azang, espíritos errantes dos mortos e os espíritos dos animais (Wagley e Galvão 1961).

\subsection{Suruí e Akuáwa-Asuriní}

Os dados obtidos em nossas pesquisas entre os Suruí e os AkuáwaAsuriní, realizadas entre 1961 e 1966, nos levaram a considerar os karuara como um tipo especial de espíritos, diferente dos owera, espíritos que abandonam o corpo quando as pessoas dormem, permitindo a entrada dos asonga, espíritos que provocam os sonhos. Os karuara são invocados pelos pai'é (xamãs) para curarem as doenças, mas quando descontrolados são causadores das mesmas e podem até mesmo provocar a morte.

São os karuara que chegam através da fumaça do petym (tabaco) e possibilitam o transe dos xamãs. Dominados por estes, são conduzidos até a presença de uma sawara (onça), espírito protetor dos xamãs. O controle dos karuara através do ritual xamanístico proporciona a retirada do karema. Este é retirado do corpo do doente, através da sucção, pelo xamã, que o mostra ao paciente. O karema pode ser uma coisa ou um "bicho", geralmente o corpo de uma pequena abelha.

Como disse, a primeira vez que ouvi os Suruí se referirem a karuara foi quando demonstraram medo em entrar em uma gruta, que denominam itakuara. Este receio foi confirmado, no ano seguinte, entre os Asuriní, 
quando Tehapyhykáwa nos disse que os mortos atingem a iwaga através da itakuara e que no interior da mesma existem karuara. Estes matam quem entra na itakuara e, acrescentou, até o sapo cururu morre se for lá dentro. Dois meses depois, assisti a um ritual, denominado opetimo (literalmente, ele come fumo), que considerei como um rito de iniciação de pajé. Nakawa'é, o pajé, informou-me que "só tira o bicho quem tem karuara dentro de si." E que o jovem iniciando, Itapikurú, estava fazendo o que fazem todos os Asuriní para ver se aprendem a tirar o bicho (karema). Mas Itapikurú não entrou em transe e, assim, não recebeu o karuara. Aprendi depois que aquele foi um ritual improvisado. Dez anos depois, em outra circunstância, ele foi melhor observado por Lúcia Andrade.

\subsection{Ka’apór}

Em 1967, realizamos uma pesquisa de campo entre os índios Ka’apór, estudados anteriormente por Darcy Ribeiro. Foram infrutíferos os nossos esforços em encontrar a palavra karoara entre eles. Não encontramos nenhum termo equivalente e, surpreendentemente, negaram a existência de pajés. Diziam que estes só existiram no passado e que eram homens com olhos vermelhos e desprovidos de sexo. Tal fato sempre me causou estranheza, tendo em vista que os outros grupos Tupí-Guaraní do Maranhão, como os Tenetehára e os Tembé, conhecem muito bem o termo. Muitos anos depois, quando li os Diários Índios de Darcy Ribeiro, constatei também o espanto do mesmo pela ausência de pajés!

\subsection{Ainda Suruí e Akwáwa-Asuriní}

A nossa dificuldade de comunicação linguística com os Suruí, em 1961 e 1966, e com os Suruí e os Asuriní, em 1962, não nos permitiu avançar muito sobre o tema. De certa forma, coube a Lúcia de Andrade dar prosseguimento a nossa busca em seus períodos de campo de 1982 a 1984. Em sua dissertação de mestrado, ela nos fala da primeira vez que ouviu os mesmos falarem de karuara:

Fazia nove dias que eu havia chegado à aldeia Asuriní quando, pela primeira vez, ouvi falar de KAROWARA. O tema surgiu a partir de uma conversa feminina sobre menstruação. Nesta ocasião, algumas mulheres explicaram-me que neste estado deveriam dormir longe de seus maridos, evitando as relações sexuais. Em seguida, elas começaram a falar sobre os KAROWARA. O KAROWARA, diziam elas, é colocado 
nos homens pelo pajé. Quando o pajé fuma, o KAROWARA "sobe" e fica na sua cabeça. Os KAROWARA, explicaram elas, comem animais vivos, crus, pela boca dos humanos. As mulheres mencionaram ainda o caso de um homem que teve o seu coração mordido por um KAROWARA. (Andrade 1992:82)

Lúcia Andrade ficou surpresa ao constatar que apesar da primeira informação recebida, segundo a qual o pajé colocava o karuara dentro do homem, a maioria das informações obtidas depois tratava exatamente do contrário: "o pajé retirava o KAROWARA do corpo do indivíduo, isto é, curava-o" (Andrade 1992:83).

Porém, ambas estavam corretas: possuir um desses espíritos é a possibilidade que os homens têm de poder se aproximar do espírito-onça, o que constitui uma forma de poder ou, até mesmo, de se transformar em um pajé. Assim, um homem pode ter um ou vários karuara, colocados por um ou vários pajés. Contudo, nem sempre essa relação é tranquila, pois o espírito pode provocar doenças, dores de cabeça e até mesmo levá-lo à morte. Quando isso ocorre, torna-se necessária a intervenção do pajé, capaz de acalmar o espírito ou mesmo retirá-lo do corpo do homem. Para que um homem se transforme em um pajé "é necessário que ele percorra, em sonhos, um caminho cheio de perigo e chegue até sawara, o espírito onça. É nesse contato que ele receberá o KAROWARA e, assim, o poder de curar os doentes." (Andrade 1992:84).

Em outras palavras, só o espírito onça pode transformar um homem em um pajé; mas um outro pajé deve prepará-lo para essa transformação. Ou, como ainda afirma Andrade:

...um conhecimento básico sobre o xamanismo é imprescindível à formação social do homem; não se trata de um tema apenas para especialistas - o poder da cura pode ser restrito, mas o conhecimento e o contato com o sobrenatural são constitutivos da personalidade masculina. Desta forma, todo homem Asuriní é um pouco pajé.

\subsection{Asuriní do Xingu}

Entre 1976 a 1982, Regina Müller realizou os seus trabalhos de campo entre os Asuriní do Xingu, onde também registrou a presença dos karuara no sistema de crença. É verdade que há algumas diferenças importantes. Juntamente com os apikuara e tiwa eles constituem o que Müller denominou 
como os "xamãs primordiais": “...são eles os espíritos xamãs com os quais os xamãs (terrenos) entram em contato e se tornam um deles e que, no passado mítico, eram eles próprios xamãs." (Müller 1993:87).

Ao contrário dos Suruí e Asuriní do Tocantins, para os quais os karuara têm um papel central nos rituais xamanísticos, no Xingu, como vimos, eles dividem esse papel com os dois outros grupos de espíritos (tiwa e apikuara). Ali, eles são representados como um “...ser antropomorfo, com cabelos compridos, para baixo da cintura e olhos brancos.” (Müller 1993:191). São os Tiva que têm uma ligação mais forte com a onça. Mas, como acontece nos outros dois grupos, a onça tem uma forte relação com o xamanismo, a morte e o canibalismo. Assim, também nesse caso, existe um tipo de relação entre o karuara e a onça.

\subsection{Parakanã}

Nos anos 70 e 80, Antônio Carlos Magalhães realizou o seu trabalho de campo entre outro grupo Tupí-Guaraní da região do rio Tocantins, os Parakanã, que foram contatados definitivamente em 1971. Em sua tese de doutoramento, defendida na USP em 1994, ele define karuara como “...substâncias patógenas que provocam dores, quando introduzidas no corpo de alguma pessoa, ou ainda, uma força, um atributo exclusivo do xamã e encontrado nos cigarros." (Magalhães 1994:267).

Compete ao pajé, através do ritual xamanístico, retirar o karuara do corpo da pessoa. Essa substância foi ali introduzida quando ela caminhava pela mata ou colocada em seu cigarro. Ao tragar ela engole o karuara, fato que lhe provoca dores e pode conduzi-la à morte. Segundo Magalhães, “...o karuara é representado por alguma substância (aranha, caramujo, espinho, rato, pequeno galho de árvore, esporão de arraia, osso de um animal qualquer, etc.)." (Magalhães 1994:273).

O poder de curar entre os Parakanã não está limitado aos homens: “... algumas mulheres são reconhecidas como grandes "curandeiras", caso de Koema, Akykya, Xaria (já falecidas), denominadas ukaruá ma pã (a que acaba com karowara, a que come karowara).” (Magalhães 1994:278).

No entanto, na página 291, coloca em dúvida o seu entendimento de karuara como substância e não como espírito - como acontece nos três grupos citados anteriormente -, quando afirma que "o estado de transe só ocorre durante o cerimonial do opetymõ, quando novos xamãs ou aqueles já 
tarimbados exercem a atividade de contato com o karuwara, com topoa, com os espíritos dos awa ete que já morreram." Mas, ainda assim, guarda uma diferença com os Suruí e os Asuriní do Tocantins e do Xingu, entre os quais a referência é sempre aos karuara, ou seja, um grupo de seres espirituais. Magalhães, como vimos, se refere ao karuara no singular.

Carlos Fausto, que estudou os Parakanã ocidentais, chegou a uma conclusão parecida:

Entre os parakanãs, topiwara e karowara não são propriamente espíritos, como em outros grupos Tupís, mas agentes patogênicos controlados por feiticeiros. Por isso, ninguém admite publicamente tê-los visto em seus sonhos, aqueles que vêem karowaras são considerados fortes candidatos à feitiçaria, pois se os vêem os controlam, se os controlam os utilizam. (2001:339).

Mas, ainda no mesmo parágrafo, afirma que

...a concepção parakanã sobre esses entes (o grifo é meu) só pode ser apreendida indireta e fragmentariamente - antes pelas acusações de malefício do que pela realização de curas. O material só ganha consistência quando comparado ao dos asurini, onde há xamãs especialistas cujo poder reside, precisamente, no controle dos karowara.

Carlos Fausto concorda que a ideia de karuara está disseminada entre os Tupí-Guaraní, “...embora possuam relevância e significação diversa conforme o grupo.” (2001:338).

\subsection{Wayãpí e outros}

Existem menções sobre esses seres sobrenaturais entre outros autores, como, por exemplo, Dominique Gallois: "Entre os wayãpis, por sua vez, karuara é tanto sinônimo de anhanga, quanto uma das armas de agressão dos xamãs, que corta por dentro a carne das vítimas." (Gallois 1988 apud Fausto 2001:338). Oakdale também se refere aos karuat como seres das águas para os Kayabi ${ }^{4}$. Entre os Araweté é um espírito canibal das serras, segundo Viveiros de Castro (1992 apud Fausto 2001:338). Finalmente, em uma nova dissertação de mestrado sobre os Suruí, Matta da Silva ouviu de seus informantes que o karuara "...pode se apresentar sob a forma humana no interior da mata, como fogo ou fumaça no céu e na figura do sapo kururu." (2007:125). Finalmente, a linguista Ana Suelly Arruda Câmara Cabral nos

\footnotetext{
${ }^{4}$ Não é seguro que karuat seja um espírito igual aos karuara. O que nos leva a considerar essa possibilidade é o fato de os kaiabi admitirem que, no passado, os xamãs os controlavam.
} 
informa que, entre os Zo'é, a denominação é kiruára (também kiruát), um espírito temido por todos. Vive nas águas e se relaciona com o cheiro de sangue de mulheres grávidas ou recém-paridas e também com o sapo cururu. ${ }^{5}$

Não resta dúvida sobre a grande persistência da crença entre os TupíGuaraní, localizados na região norte do país, mas existem diferenças nas representações que cada grupo faz da mesma. Portanto, o que pretendemos fazer nesta parte do trabalho é buscar explicações para essa diversidade.

Um primeiro conjunto de dados (que inclui Araweté, Asuriní, Kayabí, Suruí, Tenetehára, Wayãpi, e Zo'é) considera karuara como uma espécie de espíritos, que existem independentemente dos homens e que podem ser controlados pelos xamãs, seja para introduzi-los em um corpo humano para provocar doenças ou retirá-los do corpo para efeito de cura.

Somente Fausto e Magalhães, que estudaram os Parakanã ocidentais e orientais respectivamente, afirmam que os karuara não são um espírito propriamente dito, mas uma substância patogênica. Nenhum dos dois, contudo, parece muito seguro a respeito, pois Magalhães, como vimos, afirma que “...os xamãs entram em contato com o karowara (o grifo é nosso), com topoa e com os espíritos dos awa que já morreram." Fausto, por sua vez, em dado momento refere-se aos karuara como "esses entes".

\section{A hipótese sobre os karuara}

Resumindo, a nossa hipótese continua sendo a de que os karuara são uma espécie de espíritos, que não devem ser confundidos com as almas dos mortos. As diferentes monografias sobre os Tupí em geral e os Tupí-Guaraní em particular nos mostram que eles têm um universo sobrenatural bastante amplo. A própria categoria de sobrenatural nem sempre abrange todos os seres desse universo. Alguns deles caracterizam-se pela ambiguidade: ora podem ser considerados espíritos, ora seres da própria natureza. É o caso, por exemplo, dos mama'é xinguanos, uma categoria intermediária entre animais e seres sobrenaturais. Ou, então, dos aré, que os Ka'apór acreditam que têm forma humana, quando vivem em seu mundo subterrâneo, e forma de onças, quando estão na superfície.

Em nenhum momento pretendemos buscar uma explicação verdadeira para os karuara. Entendemos que cada grupo buscou a sua própria explicação, ou melhor dizendo, cada grupo desenvolveu a sua própria variante de

\footnotetext{
${ }^{5}$ Comunicação verbal.
} 
uma mesma crença. Mas, quaisquer que sejam essas variações, é possível identificar alguns pontos em comum. Vimos que existe uma forte relação entre os karuara e grutas ou cavernas. A palavra itakuara, por outro lado, se tomada em seu sentido literal (pedra + buraco) indica que o habitat dos espíritos não necessita ser exatamente uma caverna, podendo ser simples cavidades nas rochas como é o caso da pedra do Karuara, descrita por Coudreau. Outro ponto de convergência é a relação com o sapo cururu, que costuma se esconder em cavidades nas pedras existentes nas margens dos rios ou lagoas.

É bastante forte a relação existente entre os karuara e os xamãs, que os controlam para o bem ou para o mal. Em alguns casos são eles os intermediários entre os xamãs e uma onça espírito. Nesse caso, é importante chamar a atenção para o local de destaque que a onça ocupa nas narrativas Tupí. Por fim, temos que considerar que em todas as cosmologias é possível existirem entidades que se destacam por suas ambiguidades. É o caso dos karuara que podem ser utilizados pelos xamãs para fazer o bem, como as curas, ou o mal, como os "feitiços".

\section{Considerações finais}

Começamos este artigo mostrando a presença da crença nos karuara entre os antigos Tupinambá. No decorrer do trabalho apontamos a sua continuidade entre diferentes grupos contemporâneos situados numa mesma região geográfica. Não é difícil imaginar que existe uma relação de continuidade neste caso - entre os índios atuais e os Tupinambá. Em um artigo publicado há mais de vinte anos (Laraia 1984/1985), levantamos uma hipótese que, então, consideramos muito audaciosa:

...que esses grupos (...) seriam, de certa forma, os remanescentes dos antigos Tocantins, grupo Tupinambá, que foi vítima da política de aldeamento dos jesuítas a partir da segunda metade do século XVII. Esses remanescentes seriam grupos que se afastaram cada vez mais do litoral, a fim de obter um maior distanciamento dos brancos. Esta hipótese é coerente com a ideia de que os próprios Ka'apór nada mais seriam do que os Tupinambá que no século XVII ainda ocupavam o litoral limítrofe entre o Maranhão e o Pará. Assim é que o mapa de Curt Nimuendajú indica a existência no século XIX de Urubú-Ka'apór na região litorânea do município de Viseu, mais precisamente entre 1860 e 1872. Tal fato explicaria a grande semelhança cultural entre esses índios e os seus históricos antepassados. (Laraia 1984/1985:26). 
A relação entre os Tupinambá e os Ka'apór fica mais explícita na página 31 do mesmo texto:

Por sua vez, os Ka'apor ainda recordam o tempo em que viviam no rio Capim, no Pará. No mapa etno-histórico de Curt Nimuendajú consta a presença, na segunda metade do século XIX, de Turiwára nessa localização. Acreditamos que para uma etno-história Tupí é importante saber detalhadamente qual a diferença entre Ka'apór e Turiwára. Durante a minha pesquisa entre os primeiros, fiquei convencido de que os Turiwára seriam no máximo um subgrupo Ka'apór. A única coisa diferente, segundo os nossos informantes, era que os Turiwára praticavam a antropofagia e os Ka'apór não (sic). A contradição contida nessa informação esbarrava nos depoimentos dos velhos, como Antonio-hu, que tinham participado dos rituais antropofágicos e que os narravam com mais detalhes do que os cronistas seiscentistas.

Em uma perspectiva mais atual, estou mais convencido de que a palavra Turiwára era uma outra denominação dos Ka'apór, significando algo equivalente a "moradores do Turi". O que é importante é imaginar que os grupos Tupí-Guaraní da região mesopotâmia entre o Xingu e o Tocantins descendem de um grupo Tupinambá. A denominação desse proto-grupo como Tocantins foi apenas uma hipótese, escolhida arbitrariamente, uma vez que não está sustentada por nenhum dado histórico.

Enfim, a palavra caruara persiste em nossa linguagem, com significações diferentes das de sua origem, mas a crença em karuara persiste entre os índios mencionados com significados não muito diferentes do que tinham no passado.

\section{Referências}

Andrade, Lúcia. 1992. O corpo e o cosmo. Relações de gênero e o sobrenatural entre os Asuriní do Tocantins. Dissertação de Mestrado, Universidade de São Paulo.

Coudreau, Henri. 1977. Viagem ao Xingu. Belo Horizonte: Itatiaia; São Paulo: Universidade de São Paulo.

Fausto, Carlos. 2001. Inimigos Fiéis. História, guerra e xamanismo na Amazônia. São Paulo: EDUSP.

Laraia, Roque de Barros. 1984/1985. Uma etno-história Tupí. Revista de Antropologia, 27/28:25-33. 
Laraia, Roque de Barros. 1987. Tupí, índios do Brasil Atual. São Paulo: FFLCH/USP.

Laraia, Roque de Barros; Roberto DaMatta. 1967. Índios e Castanheiros. São Paulo: Difusão Europeia do Livro.

Magalhães, Antonio Carlos, 1994. Os Parakanã: espaços de socialização e suas articulações simbólicas. Tese de Doutorado, Universidade de São Paulo.

Matta da Silva, Gilmar. 2007. Sapurahái de Karuara: mitos, instrumentos musicais e cantos entre os Suruí Aikewára. Dissertação de Mestrado, Universidade Federal do Pará.

Müller, Regina. 1993. Os Asuriní do Xingu. História e Arte. $2^{\mathrm{a}}$ edição. Campinas: Editora UNICAMP.

Nimuendajú, Curt. 1917. Sagen der Tembé Indianer. In: Zeitschrift für Ethnologie 47:281-301. Berlin. Trad.port: Sociologia 18.2:174-182,

18.3:274-282. São Paulo, 1951.

Ribeiro, Darcy. 1996. Diários Índios. Os Urubu Kaapor. São Paulo: Cia. das Letras.

Soares de Sousa, Gabriel. 1938. Tratado Descritivo do Brasil. São Paulo: Cia. Editora Nacional.

Wagley, Charles; Eduardo Galvão. 1961. Os Tenetehara. Uma cultura em transição. Rio de Janeiro: Ministério da Educação. 